\title{
ESTRUTURA ANATÔMICA DA MADEIRA E QUALIDADE DO CARVÃO DE Mimosa tenuiflora (Willd.) Poir ${ }^{1}$
}

\author{
Elisabeth de Oliveira ${ }^{2}$, Benedito Rocha Vital ${ }^{3}$, Alexandre Santos Pimenta ${ }^{3}$, Ricardo Marius Della Lucia ${ }^{3}$, \\ Ana Márcia M. Ladeira ${ }^{4}$ e Angélica de Cássia Oliveira Carneiro ${ }^{5}$
}

\begin{abstract}
RESUMO - Este trabalho objetivou determinar algumas características anatômicas e dimensões de fibras, elementos dos vasos, células do parênquima e dos raios da madeira da Mimosa tenuiflora (Willd.) Poir. Determinaramse, ainda, a fração parede das fibras e o porcentual das fibras, dos vasos, dos raios e das células parenquimatosas, bem como a densidade, rendimento e propriedades do carvão vegetal. Conclui-se que a madeira de Mimosa tenuiflora possui poros predominantemente solitários, geminados e múltiplos em agrupamento radial; poros distribuídos em porosidade difusa uniforme; parênquima axial paratraqueal vasicêntrico, vasicêntrico confluente, aliforme e aliforme confluente; raios multisseriados, bisseriados e, menos freqüentemente, unisseriados; e fibras de parede espessa e muito curtas. Obteve-se um rendimento de $39,68 \%$ em carvão vegetal, com teor de carbono fixo de $71,70 \%$, densidade igual a $0,51 \mathrm{~g} / \mathrm{cm}^{3}$, carbono fixo de 71,79 e poder calórico de $6.866 \mathrm{cal} / \mathrm{g}$.
\end{abstract}

Palavras-chave: Jurema-preta, qualidade da madeira, características anatômicas e propriedades do carvão vegetal.

\section{ANATOMICAL STRUCTURE AND CHARCOAL QUALITY OF Mimosa tenuiflora (Willd.) Poir. WOOD}

\begin{abstract}
The objective of this work was to determine anatomical characteristics, and dimensions of fibers, vessels and parenchyma and ray cells of Mimosa tenuiflora (Willd.) Poir wood. Fibers wall fraction, the percentage of fibers, vessels and ray and parenchyma cells, as well as density and charcoal production and properties were determined. The wood of Mimosa teniflora presents predominantly solitary, geminated and multiple porous in radial groups; porous distributed in uniform diffuse porosity; axial parenchyma paratracheal vasicentric, confluent vasicentric, aliform and confluent aliform; multiseriate, biseiat rays and, less frequently, uniseriate ones; very short fibers with thick walls. Charcoal yield was $39.68 \%$ with a $0.51 \mathrm{~g} / \mathrm{cm}^{3}$ density, $71.79 \%$ carbon content and $6886 \mathrm{cal} / \mathrm{g}$ calorific value.
\end{abstract}

Keywords: Mimosa tenuiflora, wood quality, anatomical characteristics and charcoal properties.

\section{INTRODUÇÃO}

Nos últimos anos, o crescimento populacional, o avanço tecnológico e a crise dos combustíveis fósseis aumentaram a pressão sobre a flora nativa de muitas regiões, em diferentes partes do mundo, incluindo o Brasil, nas mais variadas formas, com destaque para a produção de lenha e de carvão vegetal. Como a exploração, de modo geral, vem ocorrendo de forma irracional, sem atender a qualquer regime de manejo, cresce a preocupação com o uso indiscriminado das florestas, que poderá gerar, como conseqüência, o aparecimento de grandes áreas degradadas.

\footnotetext{
${ }^{1}$ Recebido em 16.09.2004 e aceito para publicação em 10.11.2005.

${ }^{2}$ Departamento de Engenharia Florestal da UFCG, Patos-PB.

${ }^{3}$ Departamento de Engenharia Florestal da UFV, Viçosa, MG.

${ }^{4}$ Engenheira Florestal - Pesquisadora da UFV.

${ }^{5}$ Programa de Pós-Graduação em Ciências Florestais da UFV.
} 
Embora a dimensão territorial da Paraíba não seja das mais significativas no contexto do país, a sua importância é evidente quando se consideram a diversidade de paisagem e a vegetação. Há grande riqueza de espécies vegetais que exercem papel fundamental para a população. Os recursos florestais são fonte de sobrevivência, e a vegetação é fonte de alimento, madeira para construção, para fins medicinais, combustível e comércio, dentre outros. Assim, na Microrregião de Patos, Estado da Paraíba, inserida na Mesorregião do Sertão Paraibano, constata-se o crescente número de atividades consumidoras de lenha como combustível, principalmente padarias, olarias e cerâmicas. Esse crescimento tem aumentado a demanda de recursos da caatinga para a produção de combustíveis lenhosos.

Caatinga é o termo genérico empregado para designar um complexo de vegetação decídua e xerófila, constituída de vegetais lenhosos e mais ou menos rica em cactáceas e bromeliáceas. Ora dominam os primeiros, ora as segundas, exibindo misturas em proporção muito variada, conforme a natureza do substrato e a secura do clima. Há, pois, nela várias formações entrelaçadas, compondo diversos tipos de caatinga (RIZZINI, 1997). A vegetação característica da caatinga, devido ao seu porte arbóreo-arbustivo com muitas ramificações e fustes tortuosos e retorcidos, limita a sua aplicação para fins industriais. Sua utilização tem sido restrita para estacas, lenha e carvão.

Embora diversas espécies da caatinga já sejam utilizadas para fins energéticos, existem poucos estudos sobre essas espécies. Segundo Johnson (1985), as principais empregadas para a produção de carvão são: jurema-preta (Mimosa hostilis), catingueira (Caesalpinia pyramidalis), angico (Anadenanthera colubrina), jucá (Caesalpinia ferrea), mororó (Bauhinia forficata), pereiro (Aspidospema pyrifolium) e craibeira (Tabebuia aurea $)^{5}$.

Oliveira (1988) citou a utilização da jurema-preta para lenha, e Tigre (1970) relatou que essa espécie produz carvão com elevado poder calorífico, que é utilizado em forjas e fundições. Segundo Miranda (1989), o pereiro e a catingueira são, também, espécies das quais se produz carvão com boas características físicas e químicas. Contudo, a utilização mais racional dos recursos florestais depende do conhecimento entre outros da estrutura e organização dos elementos celulares que determinam a sua aptidão para o uso comercial. Assim, estudos anatômicos têm sido utilizados com o objetivo de auxiliar a taxonomia e identificação de espécies. Porém, além da descrição anatômica (BURGER e RICHTER, 1991), outras propriedades, como a densidade básica (VITAL, 1984), são parâmetros que formam a base para estudos tecnológicos, visando estabelecer o seu potencial para diversos usos. Na verdade, a descrição anatômica das madeiras é de fundamental importância para a determinação de seu aproveitamento tecnológico. Essa afirmação está baseada no fato de que as dimensões, as freqüências e o arranjo dos elementos anatômicos têm grande influência sobre as propriedades físicas e mecânicas da madeira. Segundo Paula et al. (2000), é possível classificar e agrupar espécies, direcionando-as, então, para estudos tecnológicos específicos. Contudo, após uma seleção prévia, o real potencial de uma espécie para determinada utilização depende da avaliação da qualidade do produto sendo fabricado.

Um problema relacionado à utilização do carvão vegetal é a elevada variabilidade nas suas propriedades; ele sofre grande influência da madeira que lhe deu origem e do sistema de produção.

Segundo Shimoyama (1990), citado por Garcia (1995), a densidade básica é uma quantificação direta do material lenhoso, por unidade de volume, estando relacionada com muitas propriedades e características tecnológicas importantes para a produção e a utilização dos produtos florestais. A densidade é uma das características mais importantes entre as propriedades físicas, pois afeta todas as demais propriedades da madeira. Segundo Paula et al. (2000), madeira com baixa densidade é rica em parênquima axial ou radial, ou em ambos, ou em fibras de paredes finas. Normalmente, as células parenquimatosas possuem parede fina e, portanto, baixo teor de lignina.

\footnotetext{
${ }^{5}$ Nomes científicos atualizados - jurema-preta (Mimosa tenuiflora (Willd.) Poir., catingueira (Caesalpinia pyramidalis Tul.), angico (Anadenanthera colubrina (Vell.) Brenan var. cebil (Griseb.) Altchul), jucá (Caesalpinia ferrea Mart.), mororó (Bauhinia forficata Link), pereiro (Aspidospema pyrifolium Mart.) e craibeira (Tabebuia aurea (Silva Manso) Benth. \& Hook. f. ex S. Moore).
}

R. Árvore, Viçosa-MG, v.30, n.2, p.311-318, 2006 
Assim, o objetivo deste trabalho foi caracterizar a estrutura anatômica da madeira da espécie Mimosa tenuiflora (Willd.) Poir., bem como determinar alguns parâmetros de produção e de qualidade do carvão vegetal, com o intuito de estabelecer o potencial da espécie para essa atividade. A Mimosa tenuiflora (Willd.) Poir. foi selecionada porque é uma espécie já utilizada e tem boa ocorrência na região.

\section{MATERIAL E MÉTODOS}

O Estado da Paraíba está situado na parte oriental do Nordeste brasileiro, entre os meridianos de $34^{\circ} 45^{\prime}$ $54^{\prime \prime}$ e $38^{\circ} 45^{\prime} 45^{\prime}$ " de longitude oeste e os paralelos de $6^{\circ} 2$ ' 12 " e $8^{\circ} 19$ ' $18^{\prime \prime}$ de latitude sul, ocupando uma área de $56.372 \mathrm{~km}^{2}$.

A microrregião de Patos está situada na porção central do Estado da Paraíba, integrante da Mesorregião do Sertão Paraibano, em terras que correspondem à Bacia do Rio Espinharas. Com seus $2.843,5 \mathrm{~km}^{2}$, a área em foco ocupa $4,4 \%$ da superfície total do espaço paraibano $\left(56.372 \mathrm{~km}^{2}\right)$ e abrange nove municípios: Areia de Baraúna, Cacimba de Areia, Mãe Dłágua, Passagem, Patos, Quixaba, São José de Espinharas, São José do Bonfim e Santa Terezinha. A cidade de Patos é a mais importante da região, destacando-se como centro de comercialização e prestação de serviços (IBGE, 2000).

A microrregião de Patos tem uma população de aproximadamente 117.557 habitantes, o que representa 3,4\% da população da Paraíba (IBGE, 2000).

O clima da área em estudo caracteriza-se por elevadas temperaturas médias anuais $\left(26^{\circ} \mathrm{C}\right)$, pequena amplitude térmica anual $\left(5^{\circ} \mathrm{C}\right)$, médias totais anuais de precipitação que oscilam entre 500 e $800 \mathrm{~mm} / \mathrm{ano}$, apresentando ainda forte concentração de chuva, com marcada irregularidade na sua distribuição e longa estação de seca.

Para este trabalho foram selecionadas aleatoriamente nove árvores, que apresentaram boa fitossanidade, sendo três árvores em cada localidade, Fazenda NUPEÁRIDO, em Patos, PB, Fazenda Lameirão em Santa Terezinha, PB, e Fazenda Caicu em São José de Espinharas, PB, todos na Microregião de Patos, PB.

De cada árvore foram retirados toretes de $30 \mathrm{~cm}$ de altura a 0 (base), 25, 50, 75 e 100\% da altura comercial do tronco, considerada até $5 \mathrm{~cm}$ de diâmetro. Essas amostras foram identificadas e transportadas para o
Departamento de Engenharia Florestal da Universidade Federal de Viçosa, em Viçosa, MG, onde foram realizados os estudos. Na porção mediana de cada torete foi retirado um disco de 2,5 cm de espessura, o qual foi subdividido em quatro partes, em forma de cunha, passando pela medula. A primeira parte foi destinada às análises anatômicas (dimensões das fibras e dos elementos vasculares), a segunda parte destinada à determinação da densidade básica, a terceira parte destinada à carbonização e o restante reservado para estudos posteriores de outras características tecnológicas. Para a caracterização anatômica, foram utilizadas lâminas contendo os cortes histológicos: transversal, tangencial e radial. As lâminas foram preparadas por Silva (1988). As amostras foram retiradas do cerne periférico, com $1 \mathrm{~cm}$ de aresta e fervidas em água durante uma e meia a duas horas. Os cortes foram realizados em micrótomo tipo corrediça. Os cortes das seções transversais e tangencial foram coloridos com solução de verdemalaquita e os da seção radial, com solução de safranina, e foram montados com bálsamo do Canadá sobre lâminas de microscópico.

As descrições das estruturas anatômicas e mensurações dos elementos de vasos, parênquima axial e raios foram feitas em um microscópio óptico, utilizando a objetiva de 70x para corte transversal e objetiva de 500x para os cortes longitudinal, radial e tangencial, acoplada a um projetor que gera imagem que é capturada e analisada por um programa Pro-Imagem 3.2. Para a descrição anatômica, adotou-se a terminologia constante da literatura (IAWA, 1989; IBAMA, 1992).

A densidade básica foi determinada de acordo com o método de imersão em água, descrito por Vital (1984).

Para a determinação das dimensões das fibras e dos elementos vasculares, foram confeccionados palitos do material restante dos discos, compondo-se uma amostra por árvore, que foram tratados com solução macerante de acordo com o método nítrico-acético 1:5 (RAMALHO, 1987). Uma vez individualizados os elementos anatômicos, foram montadas lâminas, sendo elas mensuradas. As medições das dimensões das fibras e dos elementos vasculares foram feitas em um microscópio óptico acoplado a um projetor, que gera imagem que é capturada e analisada por um programa Pro-Imagem 3.2. Foram medidos o comprimento (objetiva 70x), a largura e o diâmetro de lúme das fibras (objetiva $1.000 \mathrm{x})$, num total de 100 fibras por árvore.

R. Árvore, Viçosa-MG, v.30, n.2, p.311-318, 2006 
Obtidas as dimensões das fibras, foram calculados:

Espessura Média $(E P)=(D-d) / 2$;

Fração Parede $(\mathrm{FP})=(2 \mathrm{P}) / \mathrm{D}) \times 100$;

Índice de Runkel(IR) $=2 \mathrm{P} / \mathrm{Lu}$;

Índice de Enfeltramento $(E F)=(C / D) \times 1.000 ; \mathrm{e}$

Coeficiente de Flexibilidade $(\mathrm{CF})=(\mathrm{Lu} / \mathrm{D}) \times 100$.

Em que:

$\mathrm{P}=$ espessura da parede;

d = diâmetro do lume;

$\mathrm{L}=$ comprimento da fibra; $\mathrm{e}$

$\mathrm{D}=$ diâmetro tangencial da fibra.

As amostras destinadas à carbonização foram transformadas em cavacos, secadas ao ar livre, homogeneizadas e levadas à estufa a $105 \pm 3{ }^{\circ} \mathrm{C}$ por 24 horas.

A carbonização foi feita em cadinho metálico com capacidade de aproximadamente $220 \mathrm{~g}$, aquecido em forno elétrico, com controle de temperatura. O controle de aquecimento foi manual, de acordo com a seguinte marcha:

$150{ }^{\circ} \mathrm{C}$ por 1 hora

$200{ }^{\circ} \mathrm{C}$ por 1 hora

$250{ }^{\circ} \mathrm{C}$ por $1: 30$ horas

$350{ }^{\circ} \mathrm{C}$ por $1: 30$ horas

$450{ }^{\circ} \mathrm{C} 30$ minutos

A carbonização ocorreu em um tempo total de cinco horas e trinta minutos, com duas repetições por amostra, totalizando 18 carbonizações. Os gases gerados foram conduzidos para um condensador tubular, com recolhimento do líquido pirolenhoso.

Após a carbonização, o rendimento gravimétrico foi determinado, dividindo-se o peso do carvão seco produzido pelo peso da madeira seca.

As análises do carvão foram realizadas em duplicatas, em que foram realizadas análises químicas imediatas, determinação do rendimento em carbono fixo, determinação da densidade verdadeira, densidade aparente e porosidade.

A composição química imediata foi feita de acordo com a Norma NBR 8112 (ABNT, 1983), com determinações

R. Árvore, Viçosa-MG, v.30, n.2, p.311-318, 2006 de materiais voláteis, teor de cinzas e teor de carbono fixo, em base seca. O rendimento em carbono fixo foi obtido pelo produto entre teor de carbono fixo e rendimento gravimétrico da carbonização.

A densidade verdadeira e aparente do carvão e a porosidade foram feitas de acordo com as ASTMD-167-73, adaptada por Oliveira et al. (1982).

O poder calorífico superior foi determinado por meio de um calorímetro adiabático, conforme a Norma NBR 8633 (ABNT, 1983).

Foi determinado o rendimento em líquido pirolenhoso obtido em relação ao peso de madeira seca carbonizada.

\section{RESULTADOS E DISCUSSÃO}

Nas Figuras 1, 2, 3 e 4, podem ser observados os cortes anatômicos da Mimosa tenuiflora. Sua madeira caracteriza-se por possuir:

Vasos: Poros predominantemente solitários, ocorrendo também geminados e múltiplos em agrupamento radial de dois a seis poros, raramente racemiforme, cujo diâmetro médio foi de 121,96 $\mu \mathrm{m}$; variando de 30 a $155 \mu \mathrm{m}$; em média oito poros $/ \mathrm{mm}^{2}$, distribuídos em porosidade difusa uniforme (Figura 2); seção transversal circular nos poros solitários; tilos esclerosados presentes; elementos vasculares muitos curtos, $238 \mu \mathrm{m}$ de comprimento médio, variando de 219 a $267 \mu \mathrm{m}$, cuja largura média foi de $126 \mu \mathrm{m}$, variando de 108 a $136 \mu \mathrm{m}$, com apêndice curto presente em uma ou duas extremidades; com placa de perfuração simples, pontuações intervasculares opostas, areoladas, com abertura inclusa. Aárea ocupada pelos vasos é de $6,80 \%$.

Parênquima axial: Paratraqueal vasicêntrico, vasicêntrico confluente, aliforme e aliforme confluente (Figuras 1e 2), com células retangulares de maior dimensão no sentido vertical. Presença de cristais de oxalato de cálcio. A área ocupada por parênquima é de 22,93\%.

Raios: Predominam os multisseriados com três a quatro células de largura, os bisseriados e, menos freqüentes, os unisseriados; muito finos, com 14,15 $\mu \mathrm{m}$ de largura média, variando de 6,16 a $29 \mu \mathrm{m}$, extremamente baixos, e $0,10 \mathrm{~mm}$ de altura média, variando de $0,03 \mathrm{~mm}$ a $0,29 \mathrm{~mm}$, heterogêneos, formados por células procumbentes (horizontais) e quadradas (Figuras 3 e 4), pouco numerosos, de 4 a 8 raios por mm. A área ocupada pelo raio é de $13,04 \%$. 


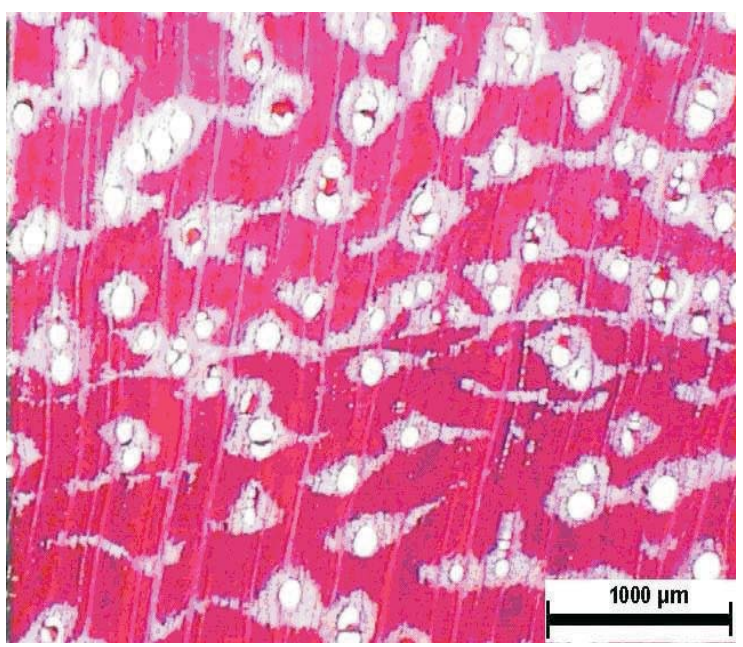

Figura 1 - Corte transversal $(70 \mathrm{X})$ mostrando porosidade, fibras abundantes (parte vermelho-escura), vasos (partes claras e ovais) e faixas de parênquima axial associados a vasos (parênquima vasicêntrico, vasicêntrico confluente, aliforme e aliforme confluente).

Figure 1 - Cross section (70X) showing porosity, abundant fibers dark red in color, vessels light in color and oval parts and strips of axial parenchyma associated to vessels (vasicentric parenchyma, confluent vasicentric, aliform and confluent aliform).



Figura 2 - Corte transversal (500X) mostrando detalhes dos elementos de vasos e parênquimas.

Figure 2 - Cross section (500X) showing heterogeneous rays composed of procumbent and square cells.

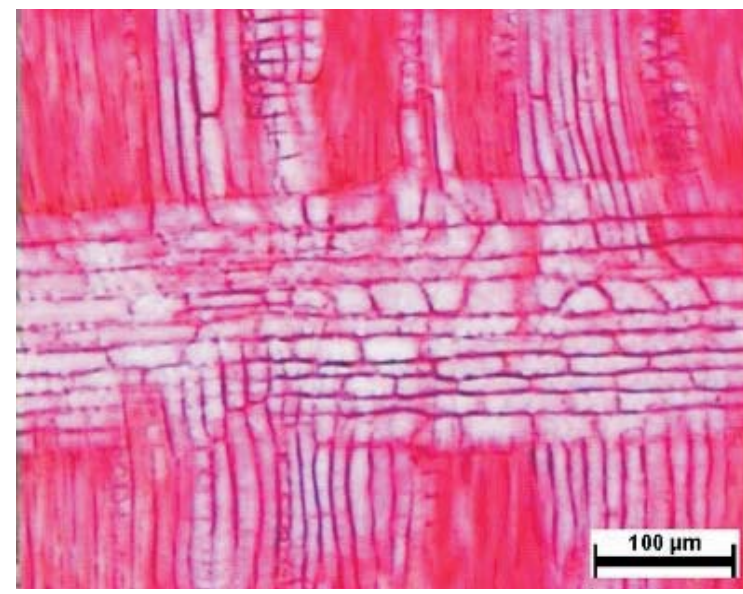

Figura 3 - Corte radial (500X) mostrando raios heterogêneos constituídos por células procumbentes e quadradas.

Figure 3 -Radial section (500X) showing heterogeneous rays composed by procumbent and square cells.

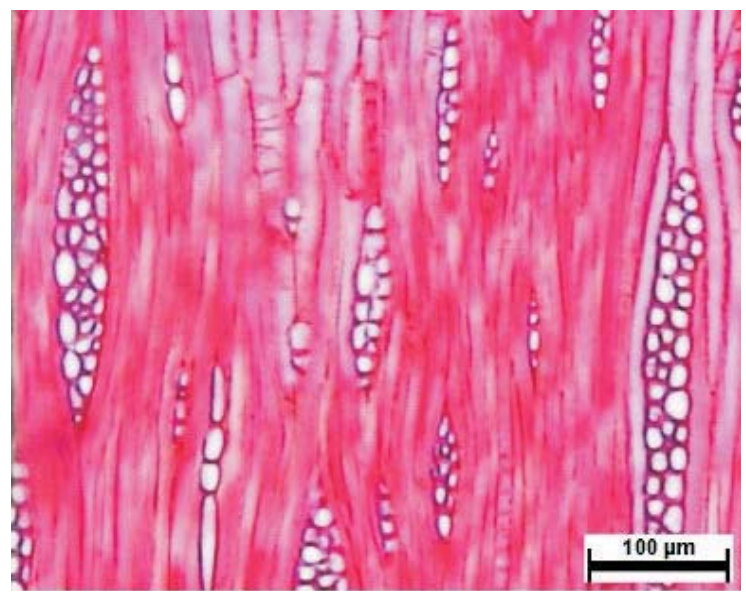

Figura 4-Corte tangencial (500X) mostrando raios multisseriados de três células de largura, os bisseriados e os unisseriados.

Figure 4-Tangencial section (500X) showing multiseriate rays with three cells wide, the biseriate and uniseriate ones.

Fibras: De paredes espessas, 5,32 $\mu \mathrm{m}$ de espessura média, variando de 4,74 a $5,83 \mu \mathrm{m}$, muito curtas, $0,75 \mathrm{~mm}$ de comprimento médio, variando de 0,64 a 0,79 mm; e com 16,43 mm de largura média, variando de 15,38 a $17,73 \mu \mathrm{m}$. A área ocupada por fibras é de $57,23 \%$.

R. Árvore, Viçosa-MG, v.30, n.2, p.311-318, 2006 
No Quadro 1, mostram-se os valores médios da densidade básica e das dimensões de fibras. No Quadro 2 , apresentam-se os valores médios das dimensões dos elementos de vasos, raios e parênquima axial, enquanto o Quadro 3 contém os resultados da carbonização e as análises do carvão.

Para a produção de carvão vegetal, é importante que a madeira apresente elevada densidade, com a conseqüente presença de fibras com elevada fração parede e baixas proporções de tecidos parenquimáticos e vasos. A espécie Mimosa tenuiflora apresenta uma madeira pesada, com uma densidade em média de 0,91 $\mathrm{g} / \mathrm{cm}^{3}$ (Quadro 1), contudo inferior ao citado por Lorenzi (1998), que foi igual a $1,12 \mathrm{~g} / \mathrm{cm}^{3}$.

A madeira apresenta um valor porcentual de vasos e parênquimas de $42,77 \%$ e porcentagem de fibras de $57,23 \%$, com uma fração parede das fibras de 64,74 (Quadro1), que é um bom indicativo da espécie para a produção de energia. Segundo Paula, (1999), madeiras com alta porcentagem de fibras com fração parede acima de $60 \%$ são de boa qualidade para gerar energia, ao contrário de madeiras ricas em parênquimas e vasos, pois estes apresentam fração parede muito baixa.
O índice de Runkel, índice de enfeltramento e coeficiente de flexibilidade encontrados foram de 1,86; 45,54 ; e $35,25 \%$, respectivamente, conforme pode ser observado no Quadro 1. O coeficiente de flexibilidade indica o grau de colapso (achatamento) que as fibras sofrem durante o processo de fabricação do papel. Nesse sentido, o índice de Runkel, na prática, tem o mesmo significado do coeficiente de flexibilidade.

A carbonização da madeira de Mimosa tenuiflora resultou em um rendimento gravimétrico em carvão de $39,68 \%$ com teor de carbono fixo de $71,97 \%$ e poder calorífico de $6.866 \mathrm{cal} / \mathrm{g}$, conforme pode ser observado no Quadro 3. Para madeira de Eucalyptus grandis, usualmente empregada na produção de carvão vegetal, carbonizada nas mesmas condições, Oliveira (2003) obteve $33,68 \%$ de rendimento gravimétrico em carvão com um teor de carbono fixo de $72,61 \%$ e densidade igual a $0,29 \mathrm{~g} / \mathrm{cm}^{3}$. Esses fatores, além da densidade aparente média do carvão de $0,51 \mathrm{~g} / \mathrm{cm}^{3}$, indicam que é possível produzir carvão de boa qualidade em termos energéticos e de rendimento com a madeira de juremapreta. Portanto, a espécie tem bom potencial para a produção de carvão e geração de energia.

Quadro 1 - Valores médios da densidade básica e das dimensões de fibras

Table 1 - Mean values of basic density and fiber dimensions

\begin{tabular}{|c|c|c|c|c|c|c|c|c|c|}
\hline Local/Árvore & $\mathrm{DBM} \mathrm{g} / \mathrm{cm}^{3}$ & $* \mathrm{~L} / \mathrm{mm}$ & $* \mathrm{D} / \mu \mathrm{m}$ & $* \mathrm{e} / \mu \mathrm{m}$ & $* \mathrm{~d} / \mu \mathrm{m}$ & $2 \mathrm{e} / \mathrm{d}$ & $\mathrm{L} / \mathrm{D}$ & $\mathrm{FP} \%$ & $\mathrm{CR} \%$ \\
\hline 1.1 & 0,94 & 0,71 & 15,38 & 4,74 & 5,90 & 1,59 & 46,16 & 61,63 & 38,36 \\
\hline 2.1 & 0,91 & 0,64 & 15,58 & 4,99 & 5,59 & 1,79 & 41,08 & 64,01 & 35,88 \\
\hline 3.1 & 0,96 & 0,78 & 15,67 & 4,81 & 6,04 & 1,59 & 49,78 & 61,39 & 38,54 \\
\hline 1.2 & 0,92 & 0,75 & 17,26 & 5,29 & 6,68 & 1,58 & 43,45 & 61,30 & 38,70 \\
\hline 2.2 & 0,91 & 0,72 & 17,25 & 5,71 & 5,84 & 1,96 & 41,74 & 66,20 & 33,86 \\
\hline 3.2 & 0,90 & 0,84 & 17,73 & 5,83 & 6,08 & 1,92 & 47,38 & 65,76 & 34,29 \\
\hline 1.3 & 0,99 & 0,76 & 16,65 & 5,31 & 6,02 & 1,76 & 45,65 & 63,78 & 36,16 \\
\hline 2.3 & 0,93 & 0,74 & 16,26 & 5,52 & 5,23 & 2,11 & 45,51 & 67,90 & 32,16 \\
\hline 3.3 & 091 & 0,79 & 16,09 & 5,69 & 4,71 & 2,42 & 49,10 & 70,73 & 29,27 \\
\hline Média & 0,91 & 0,75 & 16,43 & 5,32 & 5,79 & 1,86 & 45,54 & 64,74 & 35,25 \\
\hline C.V(\%). & 3,41 & 7,49 & 5,11 & 9,69 & 7,91 & 14,21 & 6,30 & 4,70 & 8,55 \\
\hline
\end{tabular}

* Valores médios de 100 medições; $\mathrm{DB}=$ densidade básica; $\mathrm{L}=$ comprimento $(\mathrm{mm}) ; \mathrm{D}=$ diâmetro $(\mu \mathrm{m}) ; \mathrm{e}=$ espessura da parede $(\mu \mathrm{m})$; $\mathrm{d}=$ diâmetro do lúme $(\mu \mathrm{m}), 2 \mathrm{e} / \mathrm{d}$, índice de Runkel; L/D = índice de enfeltramento; FP = fração parede; e CR = coeficiente de flexibilidade

Quadro 2 - Valores médios das medições de vasos, raios e parênquima axial Table 2 - Mean values of vessels, ray and axial parenchyma measures

\begin{tabular}{|c|c|c|c|c|c|c|c|}
\hline & \multicolumn{2}{|c|}{ Vasos } & \multicolumn{3}{|c|}{ Raios } & \multicolumn{2}{|c|}{ Parênquima Axial } \\
\hline & $\begin{array}{l}\text { Diâmetro } \\
(\mu \mathrm{m})\end{array}$ & $\begin{array}{l}\text { Número } \\
\left(\mathrm{mm}^{2}\right)\end{array}$ & $\begin{array}{c}\text { Altura } \\
(\mu \mathrm{m})\end{array}$ & $\begin{array}{c}\text { Largura } \\
(\mu \mathrm{m})\end{array}$ & $\begin{array}{l}\text { Número } \\
\left(\mathrm{mm}^{2}\right)\end{array}$ & $\begin{array}{c}\text { Largura } \\
(\mu \mathrm{m})\end{array}$ & $\begin{array}{c}\text { Comprimento } \\
(\mu \mathrm{m})\end{array}$ \\
\hline Média & 80,96 & 8,88 & 100,00 & 14,15 & 6,9 & 15,43 & 113,05 \\
\hline Máximo & 155,55 & 11,92 & 290,00 & 29,00 & 8,6 & 20,97 & 165,18 \\
\hline Mínimo & 28,37 & 5,11 & 30,00 & 6,16 & 4,3 & 3,46 & 66,98 \\
\hline $\mathrm{C} \mathrm{V}(\%)$ & 111,10 & 21,27 & 177,66 & 114,14 & 18,78 & 20,71 & 24,15 \\
\hline
\end{tabular}

R. Árvore, Viçosa-MG, v.30, n.2, p.311-318, 2006 
Quadro 3 - Valores médios das análises do carvão Table 3 - Mean values of charcoal analyses

\begin{tabular}{cccccccccccc}
\hline Amostra No & RG & RLC & DA & DV & U & MV & CIZ & CF & RCF & PCS \\
\hline 1.1 & 39,87 & 33,12 & 0,46 & 1,39 & 1,41 & 25,83 & 1,07 & 73,10 & 29,14 & 6969 \\
2.1 & 40,47 & 30,56 & 0,48 & 1,37 & 1,25 & 25,85 & 1,94 & 72,22 & 29,23 & 6917 \\
3.1 & 37,91 & 34,31 & 0,61 & 1,34 & 0,71 & 27,69 & 1,11 & 71,20 & 26,99 & 6955 \\
1.2 & 39,49 & 33,17 & 0,45 & 1,43 & 1,75 & 28,49 & 1,24 & 70,28 & 27,75 & 6987 \\
2.2 & 39,36 & 32,70 & 0,50 & 1,43 & 0,67 & 25,12 & 1,23 & 73,65 & 28,98 & 7039 \\
3.2 & 37,82 & 31,75 & 0,53 & 1,42 & 1,21 & 27,30 & 1,49 & 71,22 & 26,93 & 7041 \\
1.3 & 40,60 & 33,15 & 0,51 & 1,38 & 1,31 & 26,04 & 1,40 & 72,57 & 29,46 & 5814 \\
2.3 & 40,70 & 32,53 & 0,53 & 1,41 & 0,65 & 26,96 & 1,43 & 71,61 & 29,14 & 7049 \\
3.3 & 41,06 & 32,37 & 0,54 & 1,40 & 0,35 & 27,16 & 1,00 & 71,84 & 29,50 & 7020 \\
\hline Média & 39,68 & 32,63 & 0,51 & 1,40 & 1,03 & 26,72 & 1,32 & 71,97 & 28,57 & 6866 \\
\hline C.V. & 2,98 & 3,21 & 9,24 & 3,08 & 41,65 & 4,02 & 21,47 & 1,45 & 3,46 & 5,78 \\
\hline
\end{tabular}

$\mathrm{RG}=$ rendimento gravimétrico $(\%), \mathrm{RLC}=$ rendimento em líquido condensado $(\%), \mathrm{DA}=$ densidade aparente $\left(\mathrm{g} / \mathrm{cm}^{3}\right), \mathrm{DV}=\mathrm{densidade}$ verdadeira $\left(\mathrm{g} / \mathrm{cm}^{3}\right), \mathrm{U}=$ umidade $(\%), \mathrm{MV}=$ materiais voláteis $(\%), \mathrm{CIZ}=\operatorname{cinzas}(\%), \mathrm{RCF}=$ rendimento em $\mathrm{carbono}$ fixo $(\%), \mathrm{CF}=$ carbono fixo $(\%)$ e PCS $=$ poder calorífico superior $(\mathrm{cal} / \mathrm{g})$.

\section{CONCLUSÕES}

Sob a óptica dos resultados da análise anatômica, há indicações de que a madeira poderá ser utilizada para várias finalidades, porém é necessário que se confirmem seu desempenho sob outros aspectos tecnológicos.

Considerando o rendimento gravimétrico em carvão e em carbono fixo, poder calorífico e densidade aparente, conclui-se que a espécie Mimosa tenuiflora apresentou um bom potencial para a produção de carvão vegetal.

De acordo com os resultados deste estudo, aliados a informações da adaptabilidade da espécie na região, em termos de crescimento nas condições de solo e clima da região semi-árida, pode-se considerá-la apta à produção sustentada de biomassa para geração de energia, uma vez que ela apresenta potencial energético que supera o do Eucalyptus grandis W. Hill ex Maiden e muitas espécies da própria caatinga.

\section{REFERÊNCIAS BIBLIOGRÁFICAS}

ANDRADE, L. A.; REIS, M. G.; REIS, G. G. Classificação ecológica do Estado da Paraíba. Interpolação de dados climáticos por aproximação numérica. Revista Árvore, v.23, n. 1, p. 23-32, 1989.

ASSOCIAÇÃO BRASILEIRA DE NORMAS TÉCNICAS-ABNT. Normas técnicas NBR 8633. Brasília: 1983. não paginado.
ASSOCIAÇÃO BRASILEIRA DE NORMAS TÉCNICAS-ABNT. Normas técnicas NBR 8122. Brasília: 1983. não paginado.

BURGER, L. L.; RICHITER, H. G. Anatomia da madeira. São Paulo: Nobel, 1991. 154 p.

GARCIA, C. B. Anatomia, composição e propriedades de cinco madeiras Paraguaias. 1995. 126 f. Dissertação (Mestrado em Ciência Florestal) - Universidade Federal de Viçosa, Viçosa, 1995.

INSTITUTO BRASILEIRO DE GEOGRAFIA E ESTATÍSTICA - IBGE. Censo Demográfico: Paraíba. Rio de Janeiro: 2000. v. 7.

(Recenseamento Geral do Brasil. 2000).

INSTITUTO BRASILEIRO DO MEIO AMBIENTE E DOS RECURSOS NATURAIS RENOVÁVEIS IBAMA. Normas para procedimentos em estudos de anatomia de madeira: I - Angiospermae, II - Gimnospermae. Brasília. 1992. 19 p. (Serie Técnica, 15).

INTERNATIONALASSOCIATION OF WOOD ANATOMY - IAWA. Lent of microscopic features for hardwood identification. IAWA Bulletin, v. 10, n. 3, p. 220-359, 1989.

JOHNSON, D. V. Relatório sobre o manejo da caatinga, semi-árido do Nordeste Brasileiro. In: PROJETO PNUD/FAO/BRA/85/007 Natal: 1985. (Circular Técnica, 3).

R. Árvore, Viçosa-MG, v.30, n.2, p.311-318, 2006 
LORENZI, H. Árvores brasileiras: manual de identificação e cultivo de plantas arbóreas nativas do Brasil. 2.ed. Nova Odessa: 1998. v. 2. 352 p.

MirandA, G. Potencial energético de três espécies florestais da região semiárida do Nordeste do Brasil. 1989. 141

f. Dissertação (Mestrado em Ciências Florestais) - Universidade Federal do Paraná, Curitiba,1989.

OLIVEIRA, E. Correlação entre parâmetros de qualidade da madeira e do carvão de Eucalyptus grandis W. Hill ex Maiden. 1988. 47 f. Dissertação

(Mestrado em Ciências Florestais) - Universidade Federal de Viçosa, Viçosa, 1988.

OLIVEIRA, E. Características anatômicas, químicas e térmicas da madeira de três espécies de maior ocorrência no semi-árido nordestino. 2003. 122 f. Tese (Doutorado em Ciências Florestais) -

Universidade Federal de Viçosa, Viçosa, 2003

OLIVEIRA, J. B.; GOMES, P. A.; ALMEIDA, M. R. Estudos preliminares de normatização de testes de controle de qualidade do carvão vegetal. In: PENEDO, W. R. Carvão Vegetal. Belo Horizonte, CETEC, 1982. p. 7-38. (Série de Publicações Técnica, 006).
PAULA, J. E. Caracterização anatômica de madeiras nativas do cerrado com vistas à produção de energia. Cerne, v. 5, p. 26-40, 1999.

PAULA, J. E.; SILVA JÚNIOR, F. G.; SILVA, A. P. P. Caracterização anatômica de madeiras nativas de matas ciliares do Centro-Oeste brasileiro. Scientia Forestalis, n. 58, p. 73-89, 2000.

RAMALHO, R. S. O uso de macerado no estudo anatômico de madeiras. Viçosa, MG: Universidade Federal de Viçosa, 1987. 4 p.

RIZZINI, C. T. Tratado de fitogeografia do Brasil: aspectos ecológicos, sociológicos e florísticos. Rio de Janeiro: Âmbito Cultural, 1997. $747 \mathrm{p}$.

SILVA, J.O. Características dendrológicas e anatômicas da madeira de dez espécies ocorrentes no Nordeste semiárido. 1988. 109 f. Dissertação (Mestrado em Ciências Florestais) - Universidade Federal de Viçosa, Viçosa, 1988.

VITAL, B. R. Métodos de determinação da densidade da madeira. Viçosa, MG: SIF, 1984. 21 p. (Boletim Técnico, 1). 